\title{
EFEKTIVITAS PEMBELAJARAN DARING TERINTEGRASI DI ERA PENDIDIKAN 4.0
}

\author{
Riskey Oktavian ${ }^{1}$, Riantina Fitra Aldya ${ }^{2}$ \\ Universitas Kristen Indonesia ${ }^{1}$ \\ Universitas Tribhuwana Tunggadewi ${ }^{2}$ \\ riskey.oktavian@uki.ac.id ${ }^{1}$, riantinafitra@unitri.ac.id²
}

\begin{abstract}
ABSTRAK
Penelitian ini bertujuan untuk mengetahui efektivitas pembelajaran daring yang menekankan integrasi dengan lingkungan dari berbagai sumber yang ditinjau dari berbagai aspek selama era pendidikan 4.0. Menggunakan metode berupa meta-analisis jurnal, melalui berbagai macam jurnal yang berhubungan dengan variabel penelitian dikumpulkan kemudian dikaji dan ditarik suatu kesimpulan. Hasil kajian menunjukkan bahwa pembelajaran daring akan efektif jika menerapkan komponen esensial dari Laurillard yang mencangkup aspek diskursfi, adapftif, interaktif dan reflektif. Namun $76,07 \%$ memilih kombinasi pembelajaran daring sehingga penting adanya inovasi berupa integrasi dengan lingkungan mengacu pada komponen digital learning ecosystem dari Hammond yang dapat mengakomodasi gaya belajar, fleksibilitas dan pengalaman belajar peserta didik sehingga dapat memunculkan perasaan positif.
\end{abstract}

Kata Kunci: efektivitas; pembelajaran daring; lingkungan; pendidikan 4.0

\section{ABSTRACT}

This study aims to determine the effectiveness of online learning that emphasizes integration with the environment from various sources in terms of various aspects during the educational era 4.0. Using the method in the form of a meta-analysis of journals, through a variety of journals related to the research variables collected then reviewed and drawn a conclusion. The results of the study show that online learning will be effective if it applies an essential component of Laurillard which covers aspects of discourse, adaptive, interactive and reflective. However $76.07 \%$ chose a combination of online learning so it is important that innovation in the form of integration with the environment refers to the digital learning ecosystem component of Hammond that can accommodate learning styles, flexibility and learning experiences of students so that they can generate positive feelings.

Keywords: effectiveness; online learning; environment; education 4.0

\section{PENDAHULUAN}

Revolusi Industri 4.0 merupakan suatu era terjadinya perubahan di berbagai bidang lewat perpaduan teknologi secara besar-besaran. Perubahan tersebut tentu saja juga berdampak pada dunia pendidikan. Konteks pendidikan saat ini mulai terfokus pada inovasi serta penggunaan informasi, internet, dan teknologi secara maksimal. Sebagai salah satu faktor yang menunjang kompetisi dunia, perlu adanya keselarasan antar apa yang dihasilkan dari pendidikan formal dengan kebutuhan industri yang ada. Hal ini menyebabkan munculnya kompetisi daya saing di berbagai negara.

Tingkat competitiveness pada aspek inovasi di Singapura memiliki peringkat ke 5 dengan skor 59,83; Malaysia memiliki peringkat ke 35 dengan skor 43,16; sedang Indonesia memiliki peringkat ke 85 dengan skor 
29,80 dari total 126 negara.

Berdasarkan tingkat competitiveness

di negara ASEAN yang berhubungan langsung dengan pengembangan revolusi industri 4.0 yaitu aspek kesiapan teknologi dan inovasi, Singapura memimpin dengan nilai tertinggi dengan 5,3 nilai inovasi dan 6,1 untuk kesiapan teknologi pada tahun 2017-2018, dan Pada urutan kedua, Malaysia memiliki nilai 4,7 pada aspek inovasi dan 4,9 pada aspek kesiapan teknologi. Sedang Indonesia memiliki nilai 3,9 pada aspek kesiapan teknologi (Cornell University, 2018; Nitia, 2018).

Indonesia masih terus berupaya meningkatkan inovasi di bidang pendidikan khususnya pada pengajaran dan pembelajaran, karena sistem pendidikan yang berkualitas tidak terlepas dari keberhasilan guru dalam merancang dan melaksanakan proses pembelajaran. Menciptakan lingkungan belajar menjadi salah satu aspek penting untuk mewujudkan lingkungan belajar mandiri yang kondusif, dimana lingkungan belajar di era pendidikan 4.0 mengarah kepada pengembangan fasilitas yang memberikan kebebasan bagi peserta didik untuk dapat memproses kegiatan pembelajaran dengan menyediakan dukungan yang fleksibel, dan kemudahan akses, salah satunya pembelajaran melalui internet (Drouin et al., 2013). Berdasarkan hasil survei dari 128 peserta didik, 71 peserta memilih belajar secara interaktif (learning interactive), dimana $80 \%$ menyatakan bahwa email, tugas, presentasi audio, kolaborasi dan video online merupakan media yang paling bermanfaat dalam pembelajaran daring (Jamwal, 2012; Kobayashi, 2017).

Pembelajaran dianggap akan lebih berhasil apabila objek yang dipelajari merupakan objek nyata di lingkungan sekitarnya, sehingga pentingnya pembelajaran melalui visualisasi terhadap objek di lingkungan sekitar harus direalisasikan agar dapat dengan mudah mengklarifikasi pemahaman, meningkatkan minat, dan keterlibatan nyata peserta didik (Suryadharma \& Suyanto, 1993; Tan \& Waugh, 2013).Sehingga penelitian ini bertujuan untuk mengetahui efektivitas pembelajaran daring yang menekankan integrasi dengan lingkungan dari berbagai sumber yang ditinjau dari berbagai aspek.

\section{METODE PENELITIAN}

Penelitian ini merupakan penelitian deskriptif - kualitatif menggunakan metode berupa metaanalisis jurnal. Berbagai macam jurnal yang berhubungan dengan variabel penelitian dikumpulkan kemudian dikaji dan ditarik suatu kesimpulan.

\section{HASIL PENELITIAN DAN} PEMBAHASAN

Laurillard (1985), menyatakan bahwa proses pembelajaran terdiri dari empat proses komponen esensial 
yaitu harus: (1) diskursif memungkinkan diskusi antara siswa dan guru, di mana masing-masing mengungkapkan konsepsinya tentang beberapa aspek yang dijelaskan, dan bereaksi terhadap deskripsi yang lain; (2) adaptif - dimana, guru menyesuaikan interaksi siswa dengan lingkungan yang dialami peserta didik; (3) interaktif - memungkinkan siswa berinteraksi dengan cara meningkatkan pengalaman mereka; (4) reflektif - di mana siswa merenungkan pengalaman dan menyesuaikan dengan konsepsi mereka sendiri beserta deskripsi mereka tentang hal tersebut. Keempat komponen tersebut disajikan pada gambar 1 berikut:

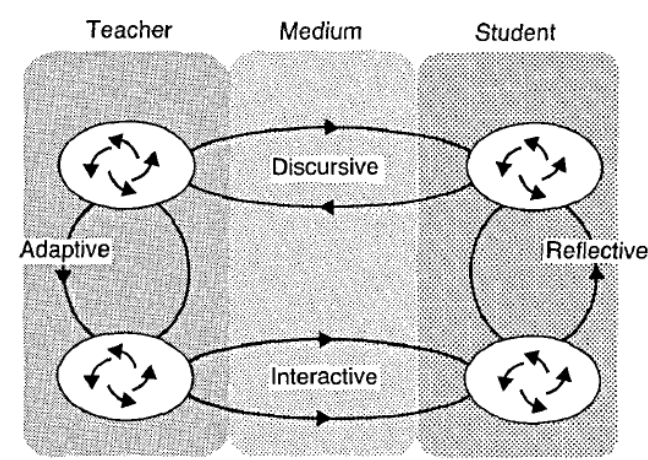

Gambar 1. Proses Pembelajaran Ideal: Hubungan Komponen Esensial (Laurillard, 1985)

Jika media tidak mendukung semua aspek pada proses pembelajaran tersebut, maka dibutuhkan representasi dari apa yang masing-masing dapat berkontribusi pada aspek tersebut. Salah satunya melalui pembelajaran daring. Pembelajaran daring telah menjadi populer karena itupotensi yang dirasakan untuk menyediakan akses dan konten lebih fleksibel, sehingga memiliki beberapa keuntungan seperti:

a. meningkatkan ketersediaan pengalaman belajar secara fleksibel sesuai dengan gaya belajarnya

b. efesiensi dalam menyusun dan menyebarluaskan konten instruksional

c. menyediakan dan mendukung kemudahan pembelajaran yang bersifat kompleks

d. mendukung pembelajaran secara "partisipatif"

e. memberikan instruksi individual dan berbedamelalui berbagai mekanisme umpan balik

f. memungkinkan mempelajari konten yang sama pada kecepatan berbeda atau untuk mencapai tujuan pembelajaran yang berbeda (Schwen \&Hara,2004;Department of Education, 2010; Fidaldo\& Thormann, 2017).

Berbagai aspek tersebut menunjukkan bahwa guru bisa lebih adaptif dalam memberikan pembelajaran secara online karena bersifat fleksibel, kemudian diskusi dapat tetap berlangsung kapan saja karena pembelajaran daring masih bersifat diskursif, dan menarik karena bersifat interaktif dengan adanya visual yang ditampilkan, dan sangat bersifat reflektif, karena pembelajaran daring dapat langsung memberikan umpan balik. Beberapa konten menarik dalam pembelajaran 
daring dipilih peserta didik karena kemudahan atau fleksibilitasnya. Menurut King et al. (2017) berikut adalah persen pemilihan peserta didik terkait aspek konten dalam pembelajaran daring yang disajikan pada tabel 1 berikut.

Tabel 1. Kecenderungan Pemilihan Peserta Didik dalam Aspek Konten Pembelajaran Daring (King et al., 2017)

\begin{tabular}{|l|c|}
\hline $\begin{array}{c}\text { Konten Pembelajaran } \\
\text { Daring }\end{array}$ & $\begin{array}{c}\text { Persentase } \\
\text { Peserta didik }\end{array}$ \\
\hline $\begin{array}{l}\text { Simulasi/ eksperimen } \\
\text { virtual }\end{array}$ & $88 \%$ \\
\hline $\begin{array}{l}\text { Catatan kehadiran } \\
\text { online }\end{array}$ & $90 \%$ \\
\hline $\begin{array}{l}\text { Penggunaan tes/ kuis } \\
\text { online }\end{array}$ & $86 \%$ \\
\hline Mind mapping & $71 \%$ \\
\hline $\begin{array}{l}\text { Fleksibilitas jam } \\
\text { pembelajaran }\end{array}$ & $85 \%$ \\
\hline Wiki sites & $74 \%$ \\
\hline
\end{tabular}

Sebagian besar praktisi untuk belajar menyukai pengguna teknologi dalam pengajaran mereka, baik bentuk pembelajaran daring sederhana. Pada aspek konten pembelajaran daring beberapa bagian yang digunakan seperti email untuk berkomunikasi, platform posting nilai secara online, wiki sites, pengujian online, hingga pemetaan pikiran sangat disukai; karena penggunaan waktu respons yang lebih fleksibel dan cepat, serta dukungan visual yang jelas dan menarik (King, et al., 2017).

$\mathrm{Hal}$ ini juga ditunjukkan berdasarkan hasil wawancara dari 117 peserta didik cenderung memilih pembelajaran daring namun sebagai tambahan dalam belajar, seperti yang disajikan pada gambar 2 berikut.

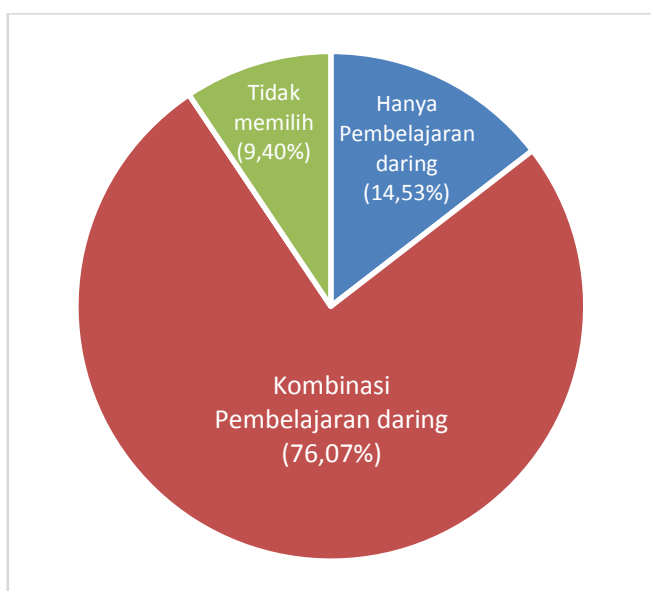

Gambar 2. Persen Kecenderungan Pemilihan Pembelajaran Daring (Pozgaj \& Knezevic, 2007)

Dari 117 peserta didik, 17 peserta (14,53\%) memilih menggunakan hanya pembelajaran daring, sedangkan 89 peserta (76.07\%) cenderung memilih kombinasi pembelajaran daring. Hal ini dikarenakan peserta didik bersedia menerima inovasi karena e-learning adalah bentuk pembelajaran baru sehingga dalam proses transisi peserta didik cenderung memilih kombinasi pembelajaran dengan pembelajaran daring (Pozgaj \& Knezevic, 2007), sehingga perlu adanya inovasi kembali dari pembelajaran daring agar peserta didik lebih adaptif, salah satunya melalui integrasi dengan lingkungannya.

Menurut Retzlaff-Fürst (2016), dalam suatu konteks lingkungan skolastik, area pembelajaran yang cocok adalah pembelajaran 
eksploratif, karena memunculkan perilaku positif sebagai hasil kombinasi dari perasaan positif, pembelajaran melalui pengalaman, dan peningkatan minat. Hammond, et al (2014), menegaskan bahwa dibutuhkan teknologi untuk mendukung suatu pembelajaran, yang disajikan pada gambar berikut:

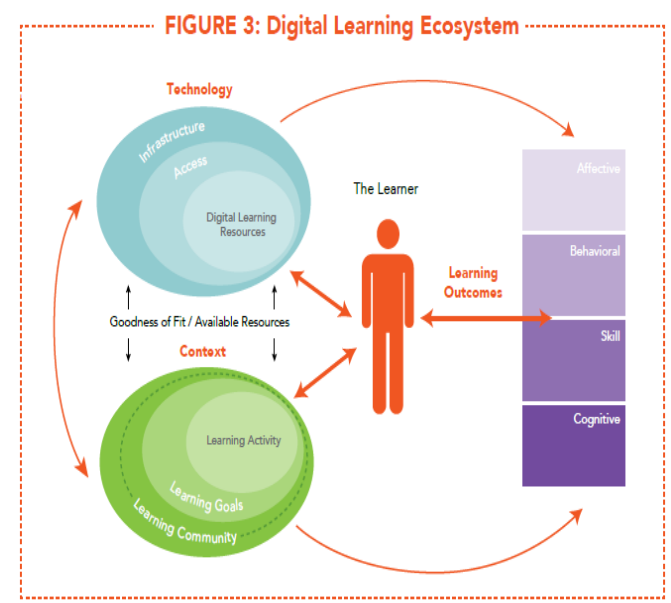

Gambar 3. Digital Learning

Ecosystem (Hammond, et al., 2014)

$$
\text { Griffiths, et al., }
$$
menyatakan bahwa pembelajaran harus berpusat pada siswa, dimana menjadi peserta aktif di lingkungan belajar mereka. Sehingga dibutuhkan banyak strategi yang mengakomodasi siswa untuk melakukan lebih banyak kontrol dan interaksi, untuk meningkatkan minat belajar mereka. Sebuah penelitian oleh Neo et al., (2015), pada peserta didik di Malaysia menyukai pembelajaran interaktif berupa daring. Hasil penelitian menunjukkan pada siswa Malaysia sebesar 86,4\% menyatakan karena kemudahan dan fleksibilitas akses,
81,8\% menyatakan mampu memahami isinya, dan $78,8 \%$ menyatakan penggunaannya yang sangat berguna serta informatif, Integrasi ini akan sangat baik untuk dilakukan mengingat pendidikan 4.0 merupakan era dimana implementasi teknologi harus benar-benar dilakukan. Aspek penting dari integrasi ini adalah akses dengan lingkungan nyata sebagai sumber daya yang ada sebagai konteks belajarakan membentuk pengalaman belajar yang luar biasa karena adanya interaksi dengan karakteristik dan lingkungan peserta didik. Perpaduan ini akan membentuk pembelajaran interaktif, penggunaan teknologi untuk mengeksplorasi dan perpaduan yang tepat antara guru dan teknologi.

\section{SIMPULAN}

Penggunaan pembelajaran daring akan menjadi sangat efektif jika memenuhi komponen esensial dalam pembelajaran yaitu diskursif, adaptif, interaktif dan reflektif dengan elemen-elemen yang akan sangat baik jika diintegrasikan dengan lingkungan pembelajar sehingga dapat menjadi pembelajaran daring yang terintegrasi dengan lingkungan atau memenuhi komponen digital learning ecosystem karena dapat mengakomodasi gaya belajar, fleksibilitas dan pengalaman belajar peserta didik sehingga dapat memunculkan perasaan positif. 


\section{DAFTAR PUSTAKA}

Cornell University, INSEAD, and WIPO. The Global Innovation Index 2018: Energizing the World with Innovation. Ithaca, Fontainebleau, and Geneva, 2018, p.xxi

Department of Education, 2010. Evaluation of Evidence-Based Practices in Online Learning: A Meta-Analysis and Review of Online Learning Studies. Office of Planning, Evaluation and Policy Development Policy and Program Studies Service. 2010DepartemenPendidikanNa sional.,2003, UndangUndangNomor20Tahun 2003 tentang Sistem Pendidikan Nasional.Jakarta:Depdiknas.

Designing for virtual communities in the service of learning, ed. S. A. Barab, R. Kling, and J.

Drouin, M., Hile, R. E.; Vartanian, L. R., \& Webb, J. 2013. Student Preferences for Online Lecture Formats. Quarterly Review of Distance Education, 14(3). pp. 151-162.

Fidaldo, P., \& Thormann, J. (2017). Reaching Students in Online Courses Using Alternative Formats. International Review of Research in Open and Distributed Learning. Volume 18, Number 2. April - 2017. Pp.140-161

Griffiths, G., Oates, B.J. \& Lockyer, M. 2007. Evolving a Facilitation Process towards Student Centred. Learning: A Case Study in Computing. Journal of Information Systems Education, 18(4) [On-line]. Diakses 7
November dari http://jise.org/Issues/18/V18N 4P459-abs.pdf

H. Gray, 154-78. Cambridge, U.K.: Cambridge University Press.

Hammond, L., Zielezinski, M.B., \& Goldman, S. 2014. Using Technology to Support At-Risk Students' Learning. USA: SCOPE (standford center for opportunity policy in education).

Jamwal, Goldee, "Effective use of Interactive Learning Modules in Classroom Study for Computer Science Education" (2012). All Graduate Plan B and other Reports. Paper 225. Pp 1-75

King, L., Jorgensen, M., Lussier, A., Fichten, C., Havel, A., Amsel, R., Poldma, T., Budd, J., Jorgensen, S., Marcil, E., Nguyen, M.N., Chauvin, A., Asuncion, J. 2017. Student and Professor Perspectives on Exemplary Practices in the Use of Information and Communication Technologies (ICTs) and e-Learning in Colleges. Montréal, Québec : Réseau de Recherche Adaptech

Kobayashi, Michiko. 2017. Students' Media Preferences in Online Learning. Turkish Online Journal of Distance Education-TOJDE. July 2017 18(3), ISSN 13026488.

Laurillard, D. 1993. Balancing the Media: Learning, Media and Technology. Journal of Educational Television. Volume 19, Number 2. pp.81-93. 
Neo, M., Park, H., Lee, M, Soh, J., \& Oh, J. 2015. Technology Acceptance of Healthcare ELearning Modules: A Study of Korean and Malaysian Students' Perceptions. TOJET: The Turkish Online Journal of Educational Technology. 14(2), April 2015.

Nitia, A. Persaingan Industri 4.0 di Asia. Dimanakah Posisi Indonesia?. Forbil Institut: Yogyakarta. 2018.

Pozgaj, Z., \& Knezevic, B. 2007. ELearning: Survey on Students' Opinions. Proceedings of the ITI $200729^{\text {th }}$ Int. Conf. on Information Technology Interfaces, June 25-28, 2007. Cavtat, Croatia.

Retzlaff-Fürst, C. 2016. Biology Education \& Health Education: A School Garden as a Location of Learning \& Well-being. Universal Journal of Educational Research. Volume 4, Number 8. pp.1848-1857

Schwen, T. M., and N. Hara. 2004. Community of practice: A metaphor for online design. In

Suryadharma, I.G.P., \& Suyanto, S. 1993. Pembelajaran Biologi Melalui Pendekatan Lingkungan Pertanian dalam Masyarakat Agrari. Jurnal Cakrawala Pendidikan. November 1993. No.3, Tahun XII.

Tan, S. \& Waugh, R. 2013. Use of Virtual-Reality in Teaching and Learning Molecular Biology. In Cai, Y. (ed.), 3D Immersive and Interactive Learning. Singapore: Springer Science Business Media Singapore. 